\section{FRACTURE OF THE FIRST RIB.}

BY

E. T. C. MILLIGAN, O.B.E., M.D., B.S., F.R.C.S.,

GURGEON TO DREADNOUGHT HOSPITAL, GREENWICH, AND THE WEIR HOSPITAL, BALHAM

$\triangle N D$

R. E. FORD, M.B., B.S.SheFF. AND LoND., HOUSE-SURGEON, WEIR HOSPITAL, BALHAM.

The following case of fracture of the first rib is interesting, both on account of its rarity and its clinical similarity to a cervical rib or exostosis.

A female, aged 17 years, complained of a swelling in the right side of the neck. The patient was unaware of its presence until it was noticed first by another girl. She had had "pins and needles" in the right hand and cramp in the arm for some time, and attributed this to an accident two months earlier, when she fell down a few stairs. She did not remember her attitude in falling, nor did she notice pain, tenclerness, or bruising. The cramp was felt when the arm was hanging by the side. and was relieved by rubbing.

Examination showed a hard bony swelling, 1 in. above the middle of the right clavicle, fixed and irregular but somewhat rounded in outline, about the size of a walnut. It was conrouncied in out!ine, about the size of a walnut. It was continuous, both in front and behind, with the first rib, into which it merod. The space between the midere of the amining fingers to be inserted. There was a slight falling amining fingers to be inserted. There was a slight falling swelling and the skin the pulsations of the subclavian artery swelling and the skin the pulsations of the subclavian artery,
which was displaced upwards and outwards, could be seen and which was displaced upwards and outwards, could be seen and
felt distinctly, giving also a thrill and bruit. The cords of the brachial plexus situated immediately behind the pulsating arter: were similarly displaced, and could be rolled over the subjacent swelling with the examining fingers. The radial pulse was altered in volume and force when the arm hung and there was no wasting. Fracture was confirmed by $x$-ray examination.

The unique features of this case are the displacement and the clinical signs and symptoms.

Displacement in fracture of the first rib is quite rare. In the case recorded displacement was the main feature attracting the notice of others to the swelling in the neck, and causing pressure signs and symptoms. In the literature there is an instance of slight displacement causing the normal curve of the rib to be slightly angular. $x$ If it is remembered that the first rib has superior and inferior surfaces with internal and external borders, it can be seen that angular displacement would more likely be upwards or downwards than outwards, which is the case in other ribs with in:ernal and external surfaces and superior and inferior borders.

Complications usually draw attention to the fracture hitherto unnoticed, so that probably the frequency of complications has been exaggerated, uncomplicated frac tures being no doubt overlooked. Abscesses above and below the clavicle have required incision and drainage. Empyema, ling abscesses, even rupture of the pleura and lung. followed by death, have occurred as complications. The case now reported is unique in its relation to the subclavian artery, which with the brachial plexus is displaced upwards and outwards.

Site of Fracture.-Fracture at the site of injury occurs by direct violence applied to the posterior and also to the anterior part of the first rib. These areas are protected by the posterior shoulder girdle muscles and the inner end of the clavicle respectively, so that great violence is needed to cause fracture. The costal cartilage and junction of the costal cartilage with the first rib have also been the site of fracture. Any part of the rib between its two extremities is subject to fracture, and the deformity angulation upwards and outwards, would fairly suggest compression force applied from either end. I This part of the rib is shielded from direct violence by overlying structures. It has been sugges'ed that t'se clavicle might act as a powerful lever, fracturing the underlying rib, like the top lever of a nutcracker, trauma on the shoulder representing the power. This mechanism can only act very rarely, if at all, and in abnormal relations of cla vicle to first rib, else fracture of the first rib would be a common occurrence, for injuries and falls on the shoulder are very frequent.

Symptoms and signs are usually so slight as to pass un. noticed, or are overshadowed by concomitant injuries. Indeed, the fracture has very often been discovered during the investigation of its complications. Still, in a few cases localized pain on breathing, or moving the shoulder girdle or neck, has been felt.

Union is the rule, as in all ribs, yet a case has been described of pseudarthrosis at the site of fracture. In the case here reported there is firm malunion.

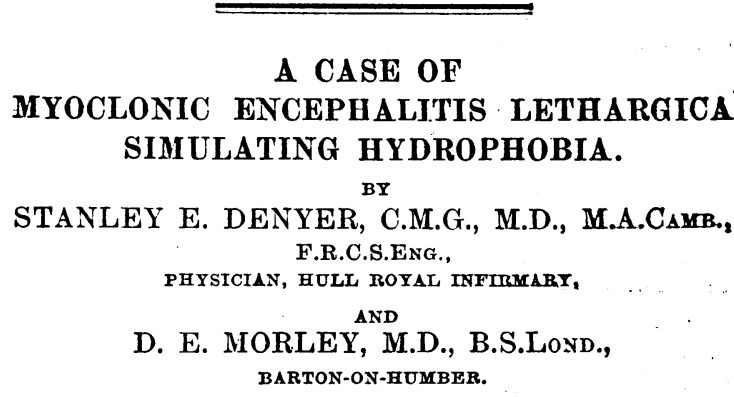

Is the discussion on epidemic encephalitis in 1918, at the Royal Society of Medicine, Dr. Crookshank pointed out that the old physicians used to describe "hydrophobia without the bite of a dog," and that this condition had also been reported in England in 1918. The following case was one in which hydrophobia was thought to be a possible diagnosis.

A. B., female, aged 25 years, up to the morning of November 11 th, 1920, was in good health, and with the exception of three attacks of influenza had had good health for many years. On the evening of November 11th she did not feel well; on November. 12th she gave up her usual occupation owing to increased feeling of illness. She was first seen by one of us (D. E. Morley) on November 13th, and appeared to be suffering from a mild influenzal attack with no special symptoms. When seen on the 14th she was distinctly excited and anxious about herself; she had vomited in the morning, and headache had herself; she had vomited in the morning, and headache had become a more marked feature. On November 15th, when seen (by D. E. M.) she became, as she had been earlier in the day, maniacal. Sitting up in bed, she shouted that her mouth was paralysed and that she was going to die. The left side of the face was weak but there was no definite paralysis. On the
16th she was wildly delirious, the most marked feature being 16th she was wildly delirious, the most marked feature being
dread of trying to swallow, and the prolonged laryngeal spasm caused by the attempt to do so. The same ideas of paralysis and death still pervaded her delirium. The condition was such as one would expect to find in a case of hydrophobia, only there was no reasonable excuse for such a diagnosis.

On November 17 th she had subsided into a semi-comatose condition and was seen in consultation (with $\mathbf{S}$. $\mathbf{E}$. Denyer). Encephalitis lethargica was diagnosed. The condition found (by S. E. D.) was as follows: Temperature $100^{\circ}$, pulse 88 , good ; limbs flaccid, no trismus, slight twitching of the facial muscles on the right side, pointing to irritation of the seventh cranial on the right side, pointing to irritation of the seventh cranial nerve. She also had occasional clonic movements of her arms. The knee-jerks were present, no Babinski, no ankle clonus, tendo Achillis jerks not obtainable, no Kernig's sign. On stroking the foot fairly hard, irregular twitching of the muscles of the outer side of the thigh took place. There had been no incontinence of urine or faeces until this day, when there was a slight incontinence of urine; the bladder was empty. Pupils react to light but are unequal, a lethargic state and did not answer questions or appear to be aware of anything that was answer questions or appear difticulty in swallowing, owing to the marked laryngeal spasm. A fluid of purulent appearance was frequently regurgitated from the throat. There was subwas frequently regurs at the root of the neck on the right cutaneous emphysema at thesent. The abdominal superficial side. Tache cerebrale was present. Thuint or ocular paralysis reflex was present. There was no squint or ocular paralysis, no cyanosis, no sweating, no rash, no retraction of the head or pain in moving the neck in any direction. She had been fed successfully with a nasal tube previously, but an attempt to repeat this set up a condition of spasm which made feeding impossible by this means. She was therefore given saline enemata containing sugar, and

of hexamine every eight hours. This treatment was continued, and on November 19th 10 grains of hexamine was administered intravenously. On November 20 th she was conscious, and a further 20 grains of hex murroundins and able to speak sensibly, though her words were incomings and able to speak sing now became possible by a stomach pletely formed. Feeding nill considerable spasm until the tube tube, though there was still considerable spasm was in position. Her general coma the reck worse, and although the emphysema at the root of the neck which had been so marked on November 17 th had completely gone, bronchopneumonia s

fatally on November 24 th.

The temperature varied from $100^{\circ}$ to $102^{\circ}$, with the exception
rises to $104^{\circ}$ and $105^{\circ}$ on the third and fourth days of the illness. 